\title{
Analysis of wheat disease resistance data originating from screenings of Gatersleben genebank accessions during 1933 and 1992
}

\author{
Andreas Börner · Ulrich Freytag • Ursel Sperling
}

Received: 18 November 2003 / Accepted: 3 June 2004 / Published online: 23 September 2006

(C) Springer Science+Business Media B.V. 2006

Erratum to: Genet Resour Crop Evol (2006) 53: 453-465

DOI 10.1007/s10722-004-1158-8

In the online version of Genet Resour Crop Evol 53 pages 453-465 uncorrected proofs were published instead of the final version of the article.
The creditline should read; (2006) 53: 453465. In Table 1, under the fourth heading; 5, 36 (447) should read 536 (447). Under the heading Leaf rust, page 456, (1071 accessions) should read (1,071 accessions).

The online version of the original article can be found at http://dx.doi.org/10.1007/s10722-004-1158-8

A. Börner $(\bowtie) \cdot$ U. Freytag

Institut für Pflanzengenetik und

Kulturpflanzenforschung, Corrensstraße 3, D-06466

Gatersleben, Germany

e-mail: boerner@ipk-gatersleben.de

U. Sperling

Landesanstalt für Landwirtschaft und Gartenbau

Sachsen-Anhalt, Silberbergweg 5, D-39128

Magdeburg, Germany 